\title{
Análise de focos de queimadas no município de Balsas/MA
}

As queimadas consistem em uma prática agrícola vastamente usada no Brasil e que causa inúmeros impactos ambientais, tais como o empobrecimento do solo e a perda da biodiversidade, saber quais são as causas e onde as queimadas acontecem com maior intensidade é de extrema importância para a criação de planos de prevenção e combate ao fogo. Diante disso, o presente trabalho objetivou quantificar o número de focos de queimadas no município de Balsas/Maranhão para o período de junho/2017 a junho/2018 (1 ano). A metodologia baseou-se em levantamento de dados de focos de queimadas fornecidos pelo INPE (Instituto Nacional de Pesquisas Espaciais) e no uso de ferramentas de geoprocessamento e de SIG (Sistema de Informações Geográficas). Com a pesquisa notou-se que mais de 800 focos de queimadas foram registrados no período estudado. Portanto, a situação observada de focos de queimadas em Balsas pode ser atribuída à susceptibilidade decorrente clima seco prolongado, mas principalmente devido às ações de queimadas criminosas, principalmente aquelas relacionadas ao desmatamento e ao avanço da fronteira agrícola, visto que é um município que a plantação de soja cresce cada dia mais. Com a pesquisa notou-se que foram registrados no município de Balsas/MA um total de 850 focos de queimadas no período estudado. Os maiores números de focos de queimadas foram registrados nos meses de junho a setembro de 2017 e no mês de junho de 2018.

Palavras-chave: Impacto ambiental; Fogo; Vegetação.

\section{Analysis of fires in the municipality of Balsas/MA}

Burning is an agricultural practice widely used in Brazil and which causes numerous environmental impacts, such as soil impoverishment and loss of biodiversity knowing what the causes are and where the fires occur with greater intensity is extremely important for the creation prevention and firefighting plans. Therefore, this study aimed to quantify the number of fires in the municipality of Balsas/Maranhão for the period from June/2017 to June/2018 (1 year). The methodology was based on data collection of fires foci provided by INPE (National Institute for Space Research) and the use of geoprocessing tools and GIS (Geographic Information System). With the research it was noticed that more than 800 fires foci were registered in the studied period. Therefore, the observed situation of fires in Balsas can be attributed to the susceptibility resulting from prolonged dry climate, but mainly due to the actions of criminal fires, mainly those related to deforestation and the advance of the agricultural frontier, since it is a municipality that plantation soybean grows more each day. With a survey that has not yet been registered in the municipality of Balsas/MA 800 foci of fires in the highest number of outbreaks of fires were recorded the months of June to September 2017 and the month of June 2018.

Keywords: Environmental impact; Fire; Vegetation.

Topic: Tecnologia, Modelagem e Geoprocessamentos

Reviewed anonymously in the process of blind peer.
Received: 06/05/2020

Approved: 02/07/2020
Jeferson Botelho Rodrigues (iD

Universidade Vale do Rio Verde, Brasil

http://lattes.cnpq.br/9702846379230129

http://orcid.org/0000-0001-6371-7912

botelhojef@outlook.com

Débora Danna Soares da Silva (id

Instituto Federal do Ceará, Brasil

http://lattes.cnpq.br/8673315906922148

http://orcid.org/0000-0002-8239-655X

dannasilva94@gmail.com

Layse Lorena Neves Sales (it)

Universidade Estadual do Maranhão, Brasi

http://lattes.cnpq.br/5078801917465786

http://orcid.org/0000-0001-7606-9475

lorenasales.eng@gmail.com

\author{
Stephanie Jael Negrão de Freitas (ic) \\ Universidade Federal do Pará, Brasil \\ http://lattes.cnpq.br/1432769722634758 \\ http://orcid.org/0000-0001-9917-5342 \\ negro.stephanie@gmail.com \\ Ana Carla Leite Carvalho Cabral ii \\ Universidade da Amazônia, Brasil \\ http://lattes.cnpq.br/6538382004505294 \\ http://orcid.org/0000-0002-1735-1320 \\ calincarvalho@gmail.com
}

Referencing this:

RODRIGUES, J. B.; SILVA, D. D. S.; SALES, L. L. N.; FREITAS, S. J. N.; CABRAL, A. C. L.. Análise de focos de queimadas no município de Balsas/MA. Nature and Conservation, v.13, n.3, p.146-151, 2020. DOI: http://doi.org/10.6008/CBPC2318-2881.2020.003.0015 


\section{INTRODUÇÃO}

O Maranhão é o estado com o maior número de queimadas no Nordeste, de acordo com dados do Instituto Nacional de Pesquisas Espaciais (INPE) divulgados em 2015, além disso, encontrava-se em $2^{\circ}$ lugar dos Estados no ranking nacional de queimadas para o mês de agosto de 2015, onde foram registrados no Brasil, 39.459 focos de queimadas, dos quais 5.428 somente no Maranhão (INPE, 2017).

As queimadas consistem em uma prática agrícola antiga e vastamente usada no Brasil, diversos autores afirmam que a ocorrência de queimadas traz inúmeros impactos ambientais, como o empobrecimento do solo, a perda da biodiversidade de flora e fauna, efeitos no balanço radiativo da atmosfera e no clima em diferentes escalas, o uso inadequado das queimadas causa também grandes perdas econômicas como a destruição de propriedades privadas, interrupção do tráfego aéreo e desligamento de redes elétricas. Além dos efeitos aos ecossistemas, os poluentes gerados pela queima de biomassa proporcionam efeitos deletérios à saúde humana (ARTAXO et al., 2005; GIGANTE et al., 2007; MÉLO et al., 2011).

As queimadas que acompanham o desmatamento determinam as quantidades de gases emitidas não somente da parte da biomassa que queima, mas também da parte que não queima. Quando há uma queimada, além da liberação de gás carbônico (CO2), são liberados também gases-traço como metano (CH4), monóxido de carbono (CO) e nitroso de oxigênio (N2O). A parte da biomassa que não queima na queimada inicial, que é quente, com chamas, também será oxidada. Parte disto ocorre por processos de decomposição (com alguma emissão de $\mathrm{CH} 4$ pela madeira consumida por cupins) e parte pelas requeimadas (queimadas das pastagens e capoeiras, que também consomem os remanescentes da floresta original ainda presentes nas áreas), queimadas estas de temperatura reduzida, com formação de brasas e maiores emissões de gasestraço (FEARNSIDE, 2002).

Assim, saber quais são as causas e onde as queimadas acontecem com maior intensidade é de extrema importância para a criação de planos de prevenção e combate ao fogo. De acordo com Fonseca et al. (2003) as atividades preventivas são mais eficientes quando baseadas em informações como em quais áreas o fogo surge com maior frequência e o que favoreceu o seu acontecimento nessas áreas. Portanto, é necessário mensurar o número de focos de calor em uma determinada área, principalmente aquelas com atividade agrícola intensa, para fins de monitoramento ambiental. Em vista disso, o objetivo deste estudo foi investigar a ocorrência de focos de queimadas no município de Balsas/MA para o período de junho de 2017 a junho de 2018 (1 ano).

\section{MATERIAIS E MÉTODOS}

\section{Área de estudo}

O município de Balsas/MA está localizado na região Sul do Estado do Maranhão, como mostra a Figura 1, possui com uma população de aproximadamente 83.528 habitantes e extensão territorial de $13.199,7 \mathrm{~km}^{2}$. 


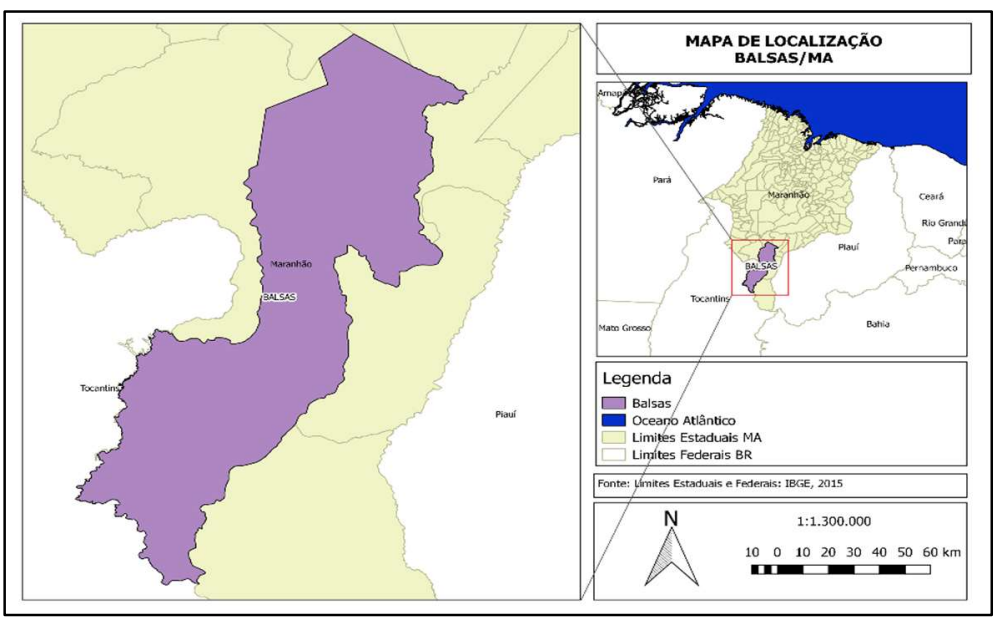

Figura 1: Mapa de localização do município de Balsas/MA.

O município de Balsas se localiza a quase $800 \mathrm{Km}$ da capital do Maranhão (São Luís), insere-se no bioma cerrado, possui clima tropical (AW') segundo a classificação de Köppen, com dois períodos bem definido: um de chuvas e de estiagem, sendo os meses de setembro, outubro, novembro e dezembro característico como o período de estiagem e de janeiro a junho marcado como período chuvoso (com precipitação mensal superior a 132,6 mm) (CORREIA FILHO, 2011).

A série temporal (jun/2017 até jun/2018) dos focos de queimadas no município de Balsas/MA foi obtida no banco de dados do Instituto Nacional de Pesquisas Espaciais. Foram utilizados os considerados apenas os focos registrados pelo satélite de referência AQUA_M-T, pois permite analisar as tendências espaciais e temporais dos focos, ao longo dos anos, em uma região, considero um dos satélites mais consistentes para estudos comparativos ao longo do tempo. Os dados de focos de queimadas do município em estudo foram adquiridos no formato shapefile. Posteriormente, utilizou-se ferramentas de geoprocessamento, para tal foi construído um banco de dados em ambiente SIG (Sistema de Informações Geográficas) no software QGis versão 2.18. Por meio da consulta espacial de intersecção no SIG, foram determinados os focos de queimada, no município para o período estudado.

\section{RESULTADOS E DISCUSSÃO}

A quantidade de focos de queimadas registradas no município de Balsas/MA no período de 01/06/2017 até 01/06/2018 é apresentada no Quadro 1 e Figura 2.

Quadro 1: Focos de queimadas no município de Balsas, para o período estudado.

\begin{tabular}{|l|l|}
\hline MÊS & № de Focos de Calor \\
\hline JUNHO/2017 & 81 \\
\hline JULHO/2017 & 81 \\
\hline AGOSTO/2017 & 121 \\
\hline SETEMBRO/2017 & 306 \\
\hline OUTUBRO/2017 & 60 \\
\hline NOVEMBRO/2017 & 0 \\
\hline DEZEMBRO/2017 & 2 \\
\hline JANEIRO/2018 & 2 \\
\hline FEVEREIRO/2018 & 5 \\
\hline MARÇO/2018 & 12 \\
\hline ABRIL/2018 & 11 \\
\hline MAIO/2018 & 36 \\
\hline JUNHO/2018 & 133 \\
\hline
\end{tabular}




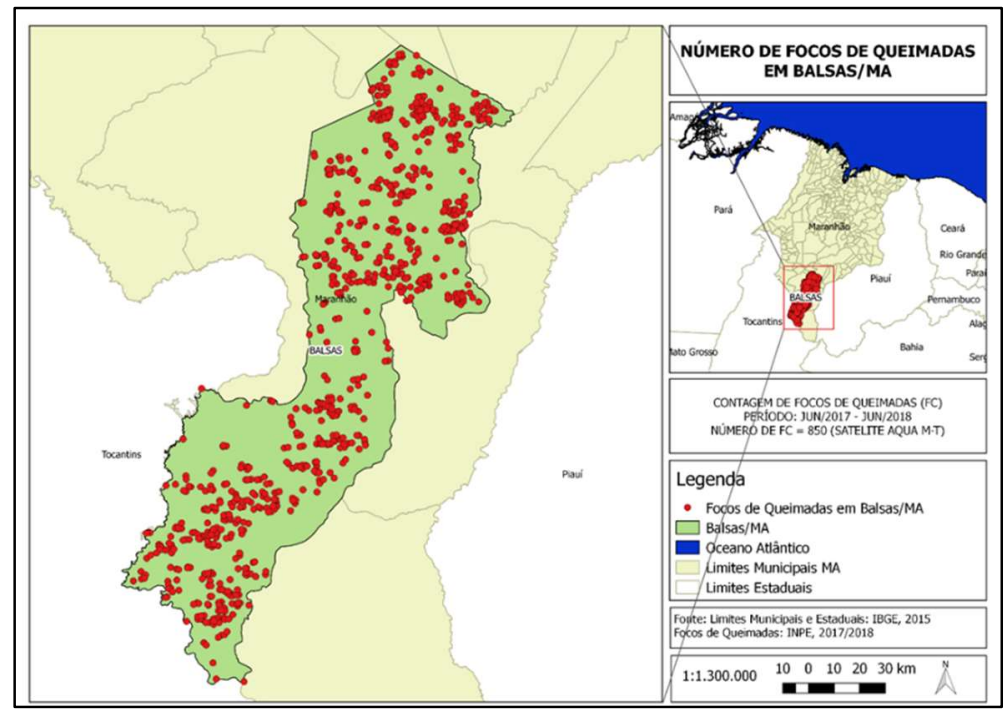

Figura 2: Focos de queimadas no município de Balsas/MA.

Foram registrados um total de 850 focos de queimadas em Balsas no período estudado. Os maiores números de focos de queimadas foram registrados nos meses de junho a setembro de 2017 e no mês de junho de 2018, registrando 81, 81, 121, 356 e 133 focos respectivamente. Em geral a ocorrência de focos de queimadas, em especial nesses meses destacados, pode estar associada com vários fatores, como a quantidade de chuva que teve nesses meses ou o aumento das atividades antrópicas, por exemplo.

Conforme estudo realizado por Sales et al. (2019) o município de Balsas apareceu nos 2 anos consecutivos da pesquisa (2014 e 2015) entre os 4 municípios maranhenses mais atingidos por focos de queimadas, registrando anualmente 1133 e 1103 focos de calor nos anos de 2014 e 2015, respectivamente. No Maranhão o período de chuvas e estiagem é bem definido, sendo os meses de dezembro, janeiro, fevereiro, março, abril e maio característico como o período chuvoso (CORREIA FILHO, 2011). Logo, observase que o maior número de ocorrência de focos foi registrado no período de estiagem (junho a novembro).

Segundo Justino et al. (2002) a maior incidência de focos de calor ocorre no Brasil no período de junho a outubro, com os menores valores de precipitação na parte central do País. Nestas condições, parte da vegetação em seu ciclo fenológico tende a perder as folhas, diminuído então as taxas de evapotranspiração. Com a queda das folhas abre-se espaço para a penetração da radiação solar que seca ainda mais gravetos, galhos e folhas, aumentando a inflamabilidade da floresta.

Diante disso, nota-se que a dinâmica das queimadas no município de Balsas/MA parece estar alinhada com a sazonalidade climática e a sua variação regional. Todavia, vale ressaltar que apesar das condições atmosféricas serem fator determinante para queimadas, quem deflagra são as pessoas. Segundo Ramos (2011) pesquisadores do INPE confirmaram que 99\% das queimadas são provocadas pelo homem e que as condições atmosféricas favorecem os incêndios, mas as principais causas são econômicas e culturais.

Alguns autores provaram que os focos de calor apresentam alta correlação com o desmatamento, estando diretamente relacionado com o uso do solo (TORRES et al., 2011; RAMOS et al., 2011). Quanto ao município de Balsas estudos realizados recentemente mostram que os focos de queimadas estão intimamente ligados com uso alternativo do solo (pastagens, agroindústrias e madeireiras), que desmata um 
grande percentual de área para essas atividades (FRANÇA, 2015).

De acordo com a análise realizada pelo Plano de Ação para a Prevenção e o Controle do Desmatamento e das Queimadas no Estado do Maranhão (PPCD/MA) em 2011, acerca do desmatamento acumulado no Estado do Maranhão até 2009, demonstra que 43\% da área monitorada já tiveram a vegetação nativa convertida em outros usos do solo. Balsas está na lista dos municípios do Maranhão com maior área de desmatamento no bioma Cerrado, no período de 2009 a 2010, estando em primeiro lugar.

O desmatamento causa desequilíbrios climáticos em razão da ausência das florestas que tinham como função gerar mais umidade do ar e absorver o calor atmosférico, desencadeando assim fenômenos como as queimadas. De acordo com pesquisa realizada entre os anos de 2008 a 2012, o aumento de 346\% de focos de queimadas no Estado do Maranhão registado no período do estudo está relacionado com o crescimento do setor agropecuário no Estado.

\section{CONCLUSÕES}

As queimadas florestais constituem um dos mais danosos eventos que provocam alterações nas formações vegetais, sejam elas naturais ou plantadas. Muitas são as causas de sua origem, entretanto, as mais frequentes e preocupantes reúnem-se em pequeno grupo onde é provinda de atividades antrópicas. Com a pesquisa notou-se que foram registrados no município de Balsas/MA um total de 850 focos de queimadas no período estudado. Os maiores números de focos de queimadas foram registrados nos meses de junho a setembro de 2017 e no mês de junho de 2018.

Dessa forma, políticas que incluem o combate ao desmatamento devem sempre estar aliadas às políticas de prevenção e combate às queimadas e aos incêndios florestais. Além disso, considera-se de grande relevância o acompanhado do monitoramento da qualidade do ar nessa região, com foco aos serviços e políticas integradas de saúde e meio ambiente.

Como se é conhecido, a maior parte dos focos de queimadas é causada por atividades humanas resultante de uma cultura habituada com a prática arcaica de atear fogo para limpar terrenos e abrir pastagens e áreas agricultáveis. Ou seja, a responsabilidade verdadeira não é do clima seco. As condições secas aumentam a susceptibilidade à queima, porém quem deflagra são as pessoas.

Portanto, a situação observada de focos de queimadas em Balsas pode ser atribuída à susceptibilidade decorrente clima seco prolongado, mas principalmente devido às ações de queimadas criminosas, principalmente aquelas relacionadas ao desmatamento e ao avanço da fronteira agrícola, visto que é um município que a plantação de soja cresce cada dia mais. Sugere-se que seja feito estudos de monitoramento na área a fim de identificar programas adequados de combate às queimadas.

\section{REFERÊNCIAS}

ARTAXO, P.; Gatti, V. L.; CÓRDOVA, M. A.; LONGO, M. K.; FREITAS, R. S.. Química atmosférica na Amazônia: A floresta e as emissões de queimadas controlando a composição da atmosfera amazônica. Acta Amazônica, v.35, p.185-196, 2005.
CORREIA FILHO, F. L.; GOMES, É. R.; NUNES, O. O.; LOPES FILHO, J. B.. Relatório diagnóstico do município de Balsas. Teresina: CPRM, 2011. 
FEARNSIDE, P. M.. Fogo e emissão de gases de efeito estufa dos ecossistemas florestais da Amazônia brasileira. Estudos Avançados, v.16, n.44, p.99-123, 2002.

FONSECA, E. M. B.; RIBEIRO, G. A.. Manual de Prevenção de Incêndios Florestais. Belo Horizonte: CEMIG, 2003.

GIGANTE, L. A.; ZAVALA, R. Z.; PEREIRA, B. D.; SILVA, G. R.; OYAMADA, C. O.. Um estudo da similaridade das queimadas entre municípios no Estado de Mato Grosso. In: CONGRESSO DA SOCIEDADE BRASILEIRA DE ECONOMIA, ADMINISTRAÇÃO E SOCIOLOGIA RURAL, 45. Anais. Londrina, 2007.

INPE. Instituto Nacional de Pesquisas Espaciais. Programa de Queimadas: Monitoramento por Satélite. São José dos Campos: INPE, 2017.

JUSTINO, F. B.; SOUZA, S. S.; SETZER, A.. Relação entre 'focos de calor' e condições meteorológicas no Brasil. In: CONGRESSO BRASILEIRO DE METEOROLOGIA, 12. Anais. Foz do Iguaçu, 2002.

MÉLO, A. S.; JUSTINO, F.; LEMOS, C. F.; SEDIYAMA, G.; RIBEIRO, G.. Suscetibilidade do ambiente a ocorrências de queimadas sob condições climáticas atuais e de futuro aquecimento global. Revista Brasileira de Meteorologia, v.26, n.3, p.401-418, 2011.

RAMOS, A. B. R.; NASCIMENTO, E. R. P.; OLIVEIRA, M. J. Temporada de incêndios florestais no Brasil em 2010: análise de série histórica de 2005 a 2010 e as influências das chuvas e do desmatamento na quantidade dos focos de calor. In: SIMPÓSIO BRASILEIRO DE SENSORIAMENTO REMOTO (SBSR), 15. Anais. São José dos Campos: INPE, 2011.

SALES, L. L. N.; SILVA, D. D. S.; LIMA, E. V.; FONSECA, G. T. C.; ALMEIDA, G. S.; RODRIGUES, J. B.. 10 municípios maranhenses mais atingidos por focos de queimadas nos anos de 2014 e 2015. Revista de Geografia, Recife, v.36, n.1, 2019.

TORRES, F. T. P.; RIBEIRO, G. A.; MARTINS, S. V.; LIMA, G. S.. Correlações entre os elementos meteorológicos e as ocorrências de incêndios florestais na área urbana de Juiz de Fora, MG. Revista Árvore, v.35, n.1, p.43-150, 2011.

A CBPC - Companhia Brasileira de Produção Científica (CNPJ: 11.221.422/0001-03) detém os direitos materiais desta publicação. Os direitos referem-se à publicação do trabalho em qualquer parte do mundo, incluindo os direitos às renovações, expansões e disseminações da contribuição, bem como outros direitos subsidiários. Todos os trabalhos publicados eletronicamente poderão posteriormente ser publicados em coletâneas impressas sob coordenação da Sustenere Publishing, da Companhia Brasileira de Produção Científica e seus parceiros autorizados. Os (as) autores (as) preservam os direitos autorais, mas não têm permissão para a publicação da contribuição em outro meio, impresso ou digital, em português ou em tradução. 